\title{
Intradialytic hypotension: Frequency, sources of variation and correlation with clinical outcome
}

\author{
Jeffrey J. SANDS, ${ }^{1}$ Len A. USVYAT, ${ }^{1,2}$ Terry SULLIVAN, ${ }^{2}$ Jonathan H. SEGAL, ${ }^{3}$ \\ Paul ZABETAKIS, ${ }^{1,2}$ Peter KOTANKO, ${ }^{2,4}$ Franklin W. MADDUX, ${ }^{1}$ Jose A. DIAZ-BUXO' \\ ${ }^{\prime}$ Fresenius Medical Care North America, Waltham, Massachusetts, USA; ${ }^{2}$ Renal Research Institute, New \\ York, New York, USA; ${ }^{3}$ University of Michigan Health System, Ann Arbor, Michigan, USA; ${ }^{4}$ Beth Israel \\ Medical Center, New York, New York, USA
}

\begin{abstract}
Intradialytic hypotension (IH) is a frequent complication of hemodialysis (HD) and is associated with increased patient mortality and cardiovascular events. We studied IH to determine its variability, correlates, and clinical impact in 13 outpatient HD facilities. Blood pressure was captured by machine download. IH was defined as $>30 \mathrm{mmHg}$ decrease in systolic blood pressure to $<90 \mathrm{mmHg}$. Risk factors were assessed by logistic regression and hospitalization by Poisson regression. Time to death and first hospitalization were assessed using Kaplan-Meier analysis in patients completing $>20$ HD treatments. We studied IH in 44,801 treatments (Tx) in 1137 patients. IH was frequent ( $17.2 \%$ of treatments) and highly variable by patient $(0-100 \% \mathrm{TX})$ and dialysis facility $(11.1-25.8 \% \mathrm{Tx}) .25 .1 \%$ of patients had no $\mathrm{IH}(0 \% \mathrm{Tx})$ and $16.2 \%$ had $\mathrm{IH}$ on $>35 \%$ Tx. Increased IH frequency was associated with age, female gender, diabetes, Hispanic origin, longer end stage renal disease vintage, higher body mass index, higher ultrafiltration volume, the second and third weekly Tx, lower pre-HD systolic blood pressure, higher difference between prescribed and achieved post-HD weight, and higher dialysate temperature. Dialysis facility was an independent predictor of $\mathrm{IH}$ frequency. Patients with $>35 \% \mathrm{IH}$ treatments had poorer survival $(P=0.036)$, and more frequent and longer hospitalization $(P=0.04, P=0.002$, respectively) than patients without $\mathrm{IH}$. In conclusion, $\mathrm{IH}$ frequency was highly variable, associated with individual facilities, patient and treatment characteristics, and correlated with mortality and hospitalization. Identifying practice patterns associated with $\mathrm{IH}$ coupled with routine reporting of $\mathrm{IH}$ will facilitate medical management and may result in the prevention of $\mathrm{IH}$, decreased mortality, and decreased hospitalization.
\end{abstract}

Key words: Blood pressure, hemodialysis, hypotension, intradialytic hypotension

Correspondence to: J. J. Sands, MD, Associate Medical Director Devices, Fresenius Medical Care, NA, 920 Winter Street, Waltham, MA 02451, USA. E-mail:

Jeffrey.Sands@fmc-na.com

\section{INTRODUCTION}

Intradialytic hypotension (IH) is reported to occur during approximately $5 \%$ to $30 \%$ of hemodialysis (HD) treatments $(\mathrm{Tx})^{1-4}$ and has been associated with increased 
patient mortality, access failure, and cardiovascular events. ${ }^{5-9}$ Despite this significant impact, $\mathrm{IH}$ is not routinely reported or aggregated in US HD facilities. This lack of categorized reporting makes it difficult to assess the overall frequency and impact of $\mathrm{IH}$ and may hinder routine medical management. Investigations of $\mathrm{IH}$ etiology have primarily focused on the patient factors associated with the development of hemodynamic instability, blood pressure (BP) variability, and specific interventions to prevent and treat $\mathrm{IH}^{10-18}$ Despite the multiplicity of reports, the majority of studies reflect a relatively limited number of HD treatments in a small number of dialysis facilities and do not provide insight into the overall incidence of IH in the broader HD population. Additionally, there is a paucity of data regarding the variation in $\mathrm{IH}$ frequency in individual patients or between dialysis facilities. The purpose of this study was to determine the variability of $\mathrm{IH}$ in individual patients and outpatient dialysis facilities, the patient and treatment factors associated with $\mathrm{IH}$, and the impact of $\mathrm{IH}$ on patient outcomes including hospitalization and mortality.

\section{METHODS}

We prospectively evaluated the epidemiology of $\mathrm{IH}$ in 13 outpatient Renal Research Institute (RRI) HD facilities in five US states (New York 4, Connecticut 3, Michigan 2, Illinois 1, North Carolina 3) between March 2011 and July 2012. The data collection was part of an ongoing quality improvement initiative with data feedback to the patients' caregivers as part of their normal clinical care. These activities are covered under patients' informed consent for treatment and do not qualify as "human research."

IH was defined as an intradialytic decrease in systolic BP (SBP) by more than $30 \mathrm{mmHg}$ to a level of less than $90 \mathrm{mmHg}$. Multiple episodes of IH during the same HD treatment were considered as one IH episode, and the HD treatment was considered to have had an IH event (IH treatment). BP was measured approximately every 30 minutes during dialysis, captured by direct machine download (iCare system, Fresenius Medical Care NA, Waltham, MA, USA) and stored in a database. Patient demographics, treatment parameters, laboratory data and clinical outcomes were obtained from the RRI clinical data warehouse. All treatments with available intradialytic BP data were included for data analysis.

Statistical analysis was performed using SAS 9.3 (SAS Institute Inc, Cary, NC). Mean, standard deviation and 95\% confidence intervals were calculated for continuous variables; frequency, 95\% confidence intervals and percent were calculated for categorical variables. Continuous variables were compared by Student $t$ test between groups. Predictors of IH were investigated with logistic regression. We built both unadjusted and adjusted models; for the latter we employed a generalized form of mixed effects models with patient-specific random effects. This adjustment takes into account the intra-patient variability in patient parameters. Time to death and time to first hospitalization were modeled by Kaplan-Meier analysis. For time to event analysis, we analyzed up to 7 months of follow-up and included only patients with more than 20 recorded treatments. Unadjusted Poisson regression was used to compare total number of hospital admissions and number of hospital days. Further, relationships between $\mathrm{IH}$, and time to death and first hospitalization were evaluated using Cox proportional hazard model adjusted for risk factors for $\mathrm{IH}$, which were significant in the aforementioned logistic regression. Please note: this analysis did not include some lab variables such as hemoglobin, serum sodium, serum $\mathrm{K}$, and albumen that have been reported associated with $\mathrm{IH}$. Significance was defined as a two-sided $\mathrm{P}$ value $<0.05$.

\section{RESULTS}

We studied 44,801 treatments in a total of 1137 patients as part of an ongoing quality improvement initiative. Patient demographics and treatment parameters are shown in Table 1. IH was common (present in 17.2\% of all treatments) and was highly variable by patient (between $0 \%$ and $100 \%$ of all treatments), facility (11.1$25.8 \%$ of all treatments) and calendar treatment date (6.8$26.9 \%$ of all treatments on a specific calendar date i.e., $\mathrm{mm} / \mathrm{dd} / \mathrm{yyyy})$. The majority of patients (75.1\%) had one or more episodes of $\mathrm{IH}$ (facility range: $63.0 \%$ to $84.8 \%$ of facility patients had $\geq 1 \mathrm{IH}$ episode) and $25.1 \%$ of patients had no episodes of IH (zero frequency: IH on $0 \%$ of their Tx; facility range: $15.2-37.0 \%$ patients with $0 \% \mathrm{IH} \mathrm{Tx}$ ). In $58.8 \%$ of patients, IH occurred in $1 \%$ to $35 \%$ (moderate frequency) of their Tx (facility range: $50.4-73.7 \%$ patients with $1-35 \% \mathrm{IH} \mathrm{Tx}$ ) and $16.2 \%$ of patients had $\mathrm{IH}$ on $>35 \%$ (high frequency) of their Tx (facility range: 10.3$33.0 \%$ patients with $>35 \%$ IH Tx) (Table 2 ).

Over and above patient-related factors, individual dialysis facilities were independently associated with the frequency of IH (expressed as \% of treatments affected with $\mathrm{IH}$ ), both without and with adjustment for patientspecific random effect (this adjustment takes into account intra-patient variability in patient parameters; Table 3; 
Intradialytic hypotension: risk-variation

Table 1 Patient demographics $(\mathrm{N}=1137)$

\begin{tabular}{|c|c|c|}
\hline & Mean & $\begin{array}{l}\text { Range between } \\
\text { facilities }\end{array}$ \\
\hline Number of patients $(\mathrm{N})$ & 1137 & \\
\hline Patients (N) per facility & 87.5 & $24-175$ \\
\hline Age (years) & $61.94(15.78)$ & $55.4-68.4$ \\
\hline \multicolumn{3}{|l|}{ Race } \\
\hline Black (\%) & 51.4 & $5.3-72.0$ \\
\hline White (\%) & 44.0 & $8.6-87.1$ \\
\hline Hispanic (\%) & 11.5 & 0-29.1 \\
\hline Male (\%) & 53.5 & $47.1-64.8$ \\
\hline Diabetic (\%) & 56.2 & $41.8-64.8$ \\
\hline \multicolumn{3}{|l|}{ Vascular access } \\
\hline $\operatorname{AVF}(\%)$ & 60.7 & $48.9-79.4$ \\
\hline AVG (\%) & 22.1 & $7.4-37.5$ \\
\hline Catheter (\%) & 16.4 & $7.2-27.2$ \\
\hline Vintage (years) & $4.51(4.26)$ & $2.95-7.89$ \\
\hline BMI $(\mathrm{kg} / \mathrm{m} \wedge 2)$ & $29.0(8.8)$ & $26.7-32.0$ \\
\hline Pre-dialysis SBP (mmHg) & $145.5(20.1)$ & $140-155$ \\
\hline Treatments with IH (\%) & 17.2 & $11.3-25.8$ \\
\hline Sodium gradient $(\mathrm{mmol} / \mathrm{L})^{c}$ & $-1.26(2.75)$ & $0-2.0$ \\
\hline Post weight - EDW (kg) & $0.62(5.1)$ & $0-2.2$ \\
\hline Blood flow (mL/min) & $428(46.8)$ & 390-488 \\
\hline Dialysate flow (mL/min) & $680.0(68.9)$ & $629-762$ \\
\hline Treatment time (min) & $216.3(29.8)$ & $201-232$ \\
\hline $\mathrm{spKt} / \mathrm{V}$ & $1.58(0.29)$ & $1.47-2.00$ \\
\hline Dialysate sodium (mmol/L) & $137(1.1)$ & $136-138$ \\
\hline Dialysate potassium (mmol/L) & $2.2(0.35)$ & $2.0-2.4$ \\
\hline Dialysate bicarbonate (mmol/L) & $35.4(1.1)$ & $35.0-37.0$ \\
\hline Dialysate temperature (Celsius) & $36.5(0.39)$ & $36.2-36.9$ \\
\hline
\end{tabular}

$\mathrm{AVF}=$ arteriovenous fistula; $\mathrm{AVG}=$ arteriovenous graft; $\mathrm{BMI}=$ body mass index; $\mathrm{EDW}=$ estimated dry weight; $\mathrm{IH}$ = intradialytic hypotension; sodium gradient = dialysate sodium-serum sodium; SBP = systolic blood pressure.

data without adjustment not shown). Increased risk of $\mathrm{IH}$ was associated with greater age, female gender, presence of diabetes, Hispanic ethnicity, longer vintage, higher body mass index (BMI), larger ultrafiltration volume (UFV), HD on the second and third weekly treatment day, lower pre-HD SBP, higher difference between prescribed post-HD weight and actually achieved post weight (calculated as achieved minus prescribed post-HD weight), and higher dialysate temperature.

Mortality and hospitalization were analyzed in the subset of patients $(N=446)$ with more than 20 recorded treatments. In this subset, time at risk was computed from the 20th treatment through December 31, 2012. For the purpose of this analysis, patients were divided into three groups based upon IH frequencies: $\mathrm{IH}$ in $0 \%$ of treatments (zero frequency), IH in 1\% to 35\% of treatments (moder- ate frequency), and $\mathrm{IH}$ in $>35 \%$ of treatments (high frequency). In these 446 patients, mortality was 11.69 deaths per 100 patient-years, hospitalization rate was 1.24 per patient year, and hospitalization days per patient year was 9.31. Mortality rate, hospital admission rates, and number of hospital days were significantly higher in patients with a high frequency of IH (Table 4).

Survival analysis demonstrated a difference in survival between these three groups $(\mathrm{P}=0.045$; Figure 1 ). Patients with highly frequent $\mathrm{IH}$ had the poorest survival $(\mathrm{P}=0.036$ compared with patients with without $\mathrm{IH}$ (zero frequency: $0 \%$ of treatments). Survival did not differ between patients with zero and moderate IH frequency (Table 4). When compared with patients with a high frequency of $\mathrm{IH}$, the adjusted hazard ratio of death was 0.45 $(\mathrm{P}=0.20)$ in patients without $\mathrm{IH}$ (zero frequency), and 
Sands et al.

Table 2 Intradialytic hypotension (IH) by clinic

\begin{tabular}{|c|c|c|c|c|c|c|}
\hline Facility & $\begin{array}{c}\text { Number of } \\
\text { patients }\end{array}$ & $\begin{array}{l}\text { Number of } \\
\text { treatments }\end{array}$ & $\begin{array}{c}\text { Treatments } \\
\text { with IH (\%) }\end{array}$ & $\begin{array}{l}\text { Patients with zero } \\
\text { frequency } \mathrm{IH}(0 \% \\
\text { treatments; \%) }\end{array}$ & $\begin{array}{c}\text { Patients with moderate } \\
\text { frequency IH (1-35\% } \\
\text { treatments; \%) }\end{array}$ & $\begin{array}{l}\text { Patients with high } \\
\text { frequency IH (>35\% } \\
\text { treatments; \%) }\end{array}$ \\
\hline Facility 1 & 76 & 2,351 & 19.1 & 21.1 & 63.2 & 15.8 \\
\hline Facility 2 & 99 & 5,537 & 18.2 & 15.2 & 73.7 & 11.1 \\
\hline Facility 3 & 24 & 646 & 19.0 & 20.8 & 62.5 & 16.7 \\
\hline Facility 4 & 139 & 2,803 & 21.3 & 30.2 & 50.4 & 19.4 \\
\hline Facility 5 & 54 & 1,606 & 23.7 & 20.4 & 55.6 & 24.1 \\
\hline Facility 6 & 114 & 7,223 & 16.2 & 21.9 & 65.8 & 12.3 \\
\hline Facility 7 & 70 & 2,634 & 19.2 & 20.0 & 60.0 & 20.0 \\
\hline Facility 8 & 69 & 2,223 & 19.7 & 29.0 & 56.5 & 14.5 \\
\hline Facility 9 & 79 & 2,193 & 15.1 & 27.8 & 58.2 & 13.9 \\
\hline Facility 10 & 73 & 3,364 & 13.6 & 37.0 & 50.7 & 12.3 \\
\hline Facility 11 & 68 & 3,650 & 19.9 & 33.8 & 52.9 & 13.2 \\
\hline Facility 12 & 97 & 2,537 & 25.8 & 15.5 & 51.5 & 33.0 \\
\hline Facility 13 & 175 & 8,034 & 11.1 & 28.6 & 61.1 & 10.3 \\
\hline Total & 1,137 & 44,801 & 17.2 & 25.1 & 58.8 & 16.2 \\
\hline
\end{tabular}

$0.40(\mathrm{P}=0.08)$ in patients with moderate $\mathrm{IH}$ frequency, respectively. Hospitalization rate and number of days spent in the hospital were associated with the frequency of $\mathrm{IH}$; patients without IH (zero frequency) experienced the least and shortest hospitalizations (Table 4). When analyzing the time to first hospitalization, we observed a significantly shorter time to first hospitalization in patients with a high frequency IH $(\mathrm{P}=0.039)$ (Figure 2$)$.

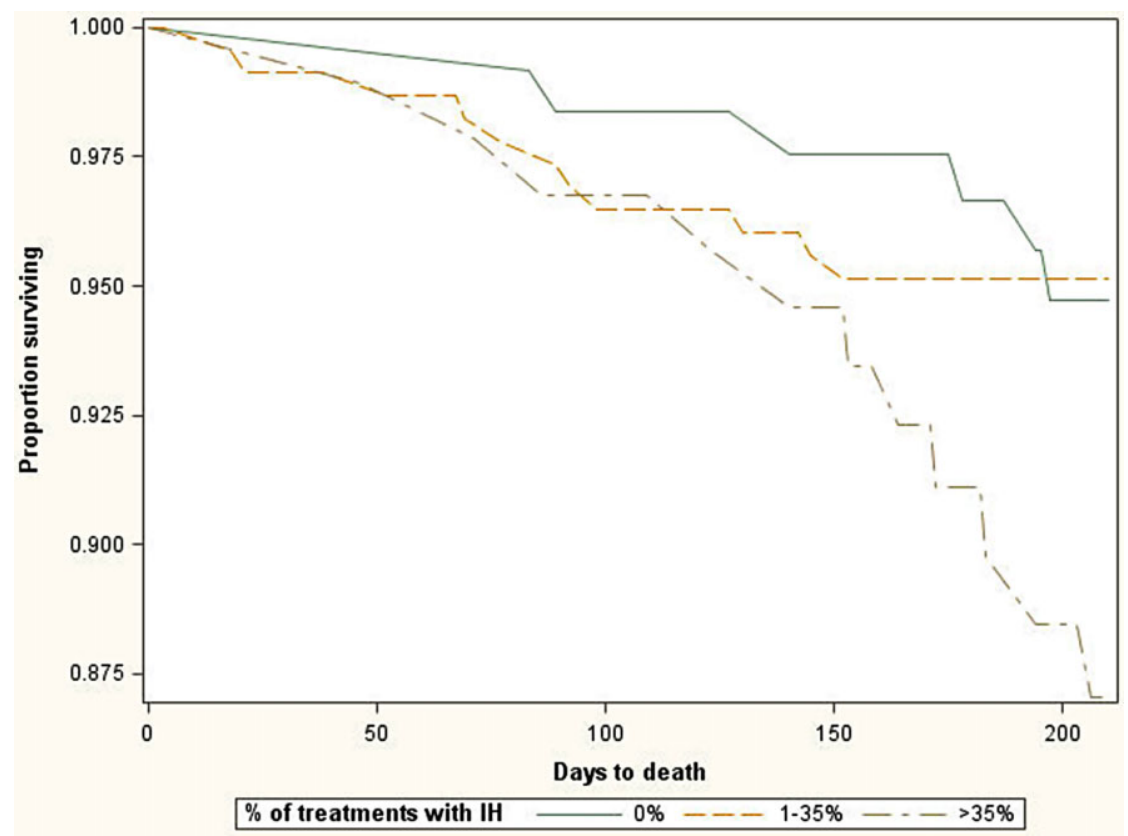

Figure 1 Time to death ( $\mathrm{N}=446)$. Patients with no (0\%) treatments (zero frequency) with intradialytic hypotension (IH) had longer survival than patients with $1 \%$ to $35 \%$ (moderate frequency) or with $>35 \%$ (high frequency) of treatments with IH (log-rank test; $\mathrm{P}=0.045)$. 
Table 3 Correlates of intradialytic hypotension (IH) by logistic regression

\begin{tabular}{|c|c|c|c|c|}
\hline & Odds ratio & $95 \%$ lower CI & $95 \%$ upper CI & $P$ value \\
\hline Age (years) & 1.020 & 1.014 & 1.025 & $<0.0001$ \\
\hline Male & 0.628 & 0.541 & 0.729 & $<0.0001$ \\
\hline Race $=$ White & 1.027 & 0.870 & 1.212 & 0.7569 \\
\hline Diabetic & 1.375 & 1.179 & 1.604 & $<0.0001$ \\
\hline Hispanic & 1.391 & 1.084 & 1.786 & 0.0095 \\
\hline Vintage (years) & 1.046 & 1.029 & 1.062 & $<0.0001$ \\
\hline Catheter & 1.170 & 0.961 & 1.424 & 0.1187 \\
\hline BMI $(\mathrm{kg} / \mathrm{m} \wedge 2)$ & 1.013 & 1.004 & 1.023 & 0.0058 \\
\hline \multicolumn{5}{|l|}{ Shift } \\
\hline Midday & 0.894 & 0.763 & 1.047 & 0.1638 \\
\hline Evening & 0.767 & 0.618 & 0.951 & 0.0155 \\
\hline \multicolumn{5}{|l|}{ Tx day } \\
\hline Second tx day of the week & 1.065 & 1.004 & 1.129 & 0.0356 \\
\hline Third tx day of the week & 1.121 & 1.057 & 1.189 & 0.0001 \\
\hline Pre-HD SBP (mmHg) & 0.986 & 0.985 & 0.988 & $<0.0001$ \\
\hline Ultrafiltration volume (L) & 1.309 & 1.251 & 1.369 & $<0.0001$ \\
\hline Treatment time (h) & 1.080 & 0.997 & 1.170 & 0.0609 \\
\hline Dialysate temperature (Celsius) & 1.077 & 1.011 & 1.147 & 0.0209 \\
\hline Achieved minus prescribed post weight $(\mathrm{kg})$ & 1.020 & 1.010 & 1.031 & 0.0002 \\
\hline Dialysate sodium $(\mathrm{mmol} / \mathrm{L})$ & 1.015 & 0.950 & 1.084 & 0.6593 \\
\hline Dialysate potassium (mmol/L) & 0.948 & 0.797 & 1.127 & 0.5447 \\
\hline Facility 3 & 0.889 & 0.558 & 1.414 & 0.6185 \\
\hline Facility 4 & 1.087 & 0.819 & 1.443 & 0.5651 \\
\hline Facility 5 & 1.387 & 1.024 & 1.879 & 0.0346 \\
\hline Facility 6 & 0.906 & 0.684 & 1.201 & 0.493 \\
\hline Facility 7 & 1.032 & 0.734 & 1.450 & 0.8582 \\
\hline Facility 8 & 1.031 & 0.704 & 1.510 & 0.8745 \\
\hline Facility 9 & 0.859 & 0.606 & 1.218 & 0.3934 \\
\hline Facility 10 & 0.746 & 0.514 & 1.081 & 0.1212 \\
\hline Facility 11 & 1.078 & 0.746 & 1.556 & 0.6896 \\
\hline Facility 12 & 1.333 & 1.007 & 1.763 & 0.0446 \\
\hline Facility 13 & 0.618 & 0.458 & 0.833 & 0.0016 \\
\hline
\end{tabular}

Odds ratio with $\mathrm{IH}$ as outcome by treatment with adjustment for random patient effect (for 1 unit change in the predictor variable). Reference $=$ non-White, non-diabetic, female gender, treated in Facility 1 and 2, treated in the morning, and treated on the first tx day of the week.

$\mathrm{CI}=$ confidence interval

Table 4 Mortality and hospitalization in patients with $\geq 20$ treatments $^{a}$

\begin{tabular}{lccccc}
\hline $\begin{array}{l}\text { Percent of treatments } \\
\text { with IH }\end{array}$ & $\begin{array}{c}\text { Number of } \\
\text { patients }\end{array}$ & $\begin{array}{c}\text { Number of } \\
\text { treatments }\end{array}$ & $\begin{array}{c}\text { Deaths } \\
\text { per } 100 \text { pt yrs }\end{array}$ & $\begin{array}{c}\text { Hospital admissions } \\
\text { per pt yr }\end{array}$ & $\begin{array}{c}\text { Hospital days } \\
\text { per pt yr }\end{array}$ \\
\hline Zero $(0 \%)$ & 123 & 2460 & 8.90 & 1.10 & 8.90 \\
Moderate $(1-35 \%)$ & 230 & 4600 & $8.9(\mathrm{P}=0.999)$ & $1.21(\mathrm{P}=0.47)$ & $9.02(\mathrm{P}=0.725)$ \\
High $(>35 \%)$ & 93 & 1860 & $22.4(\mathrm{P}=0.036)$ & $1.5(\mathrm{P}=0.04)$ & $10.84(\mathrm{P}=0.0002)$ \\
Total & 446 & 8920 & 11.69 & 1.24 & 9.31 \\
\hline
\end{tabular}

${ }^{a} \mathrm{P}$ values for comparison with patients with low IH frequency ( $<1 \%$ treatments).

$\mathrm{IH}=$ intradialytic hypotension. 


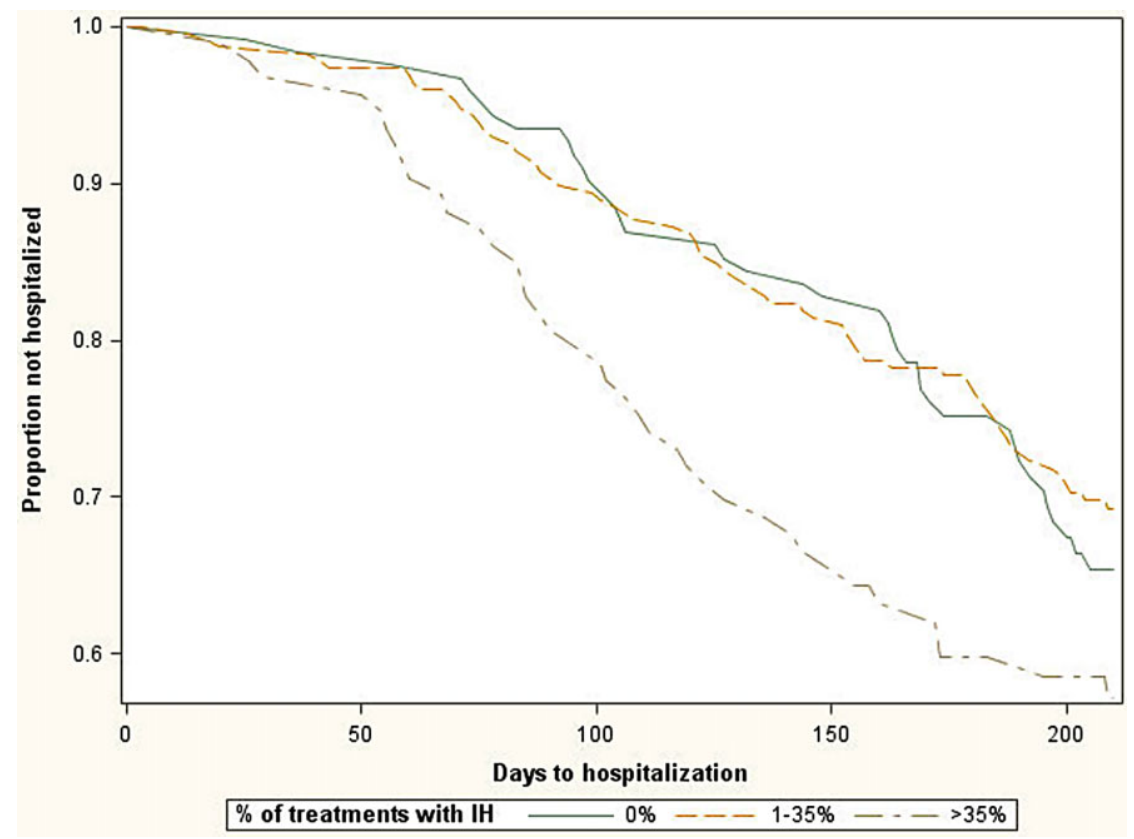

Figure 2 Time to first hospitalization $(\mathrm{N}=446)$. Patients with $>35 \%$ (high frequency) of treatments with intradialytic hypotension (IH) had a shorter time to first hospitalization than patients with $0 \%$ (zero frequency) or $1 \%$ to $35 \%$ (high frequency) of treatments with IH (log-rank test; $\mathrm{P}=0.039$ ).

\section{DISCUSSION}

IH is a frequent complication of HD therapy ${ }^{1-4}$ with significant impact upon patient outcomes. ${ }^{4-9}$ In this study, IH was present in $17.2 \%$ of all treatments in a large sample size of 1137 patients with more than 44,800 treatments. This IH frequency is consistent with previous reports and emphasizes the clinical significance of the problem of $\mathrm{IH}$. Shoji et al. ${ }^{6}$ reported an increased risk in mortality at 2 years in patients with a $\geq 40-\mathrm{mmHg}$ intradialytic fall in SBP during one HD treatment. Our data extend this observation by linking increased hospitalization, hospitalized days, and mortality to an increased frequency of treatments with IH episodes. Mechanistically, this is also consistent with reports linking IH with myocardial stunning and adverse outcomes. ${ }^{9}$

Although the pattern of change in BP during HD has been previously reported, ${ }^{10}$ the high variability of $\mathrm{IH}$ frequency between facilities, independent of patient characteristics and treatment parameters, has been largely unappreciated, unreported, and not actively managed. This variability of IH frequency among outpatient facilities is likely the result of unrecognized variations in practice patterns and provides a fertile opportunity to improve patient outcomes. In particular, the facility level variation of $\mathrm{IH}$ frequency, given the association with adverse patient outcomes, ${ }^{4-9}$ makes $\mathrm{IH}$ an attractive target for quality improvement initiatives. Numerous studies have evaluated potential therapeutic interventions to decrease IH. These include use of lowtemperature dialysate, ${ }^{1,13,14}$ decreasing the ultrafiltration rate, ${ }^{11,12}$ longer and more frequent dialysis, ${ }^{11,15}$ the use of hemodialfiltration, ${ }^{16}$ means to lower interdialytic weight gain, ${ }^{11}$ high dialysate calcium, ${ }^{19}$ biofeedback control of ultrafiltration and infusion ${ }^{20}$, and adjustment of dialysate sodium. ${ }^{21}$ All these studies agree that IH has a high clinical impact and proposed multiple potential therapeutic interventions. However, IH is not consistently defined, regularly aggregated, or reported in US outpatient dialysis facilities. This lack of routine reporting limits the medical management of $\mathrm{IH}$ and often leaves attending nephrologists unaware of the frequency their patients experience $\mathrm{IH}$. These gaps in reporting offer an enticing potential avenue to improve patient's clinical outcomes. We hypothesize that patient outcomes can be improved through active and routine reporting, tracking and treating of $\mathrm{IH}$ as part of ongoing clinical care and the facility quality improvement process. Further studies are necessary to determine whether such active reporting and routine assessment and management of $\mathrm{IH}$ will lead to improved patient outcomes, decreased hospitalization, and decreased cost of care. 
Maduell et al. ${ }^{22}$ recently reported that the incidence of symptomatic IH was 679.2 episodes per 100 patient-years ( $4.03 \%$ treatments) with online hemodiafiltration and 937.7 episodes per 100 patient-years ( $6.01 \%$ treatments) with HD. Despite different IH definitions (our study did not capture symptomatic IH vs. non-symptomatic IH), one can speculate that these markedly lower rates of $\mathrm{IH}$ may contribute to the lower mortality rates for end-stage renal disease patients reported in Europe when compared with patients in the United States. ${ }^{23}$

Most of the individual factors associated with $\mathrm{IH}$ frequency (increased age, female gender, diabetes, vintage, UFV, etc.; Table 3) were anticipated; however, the lower risk of $\mathrm{IH}$ on the first HD day of the week was unexpected. This may be related to the other adjustments including UFV in the model. Moreover, dialysis treatment time and dialysate sodium were not significantly associated with $\mathrm{IH}$ frequency. This lack of significance may relate to the limited range of treatment times $(216.3 \pm 29.8$ minutes $)$ and the relatively uniform prescribed dialysate $\mathrm{Na}$ $(137 \pm 1 \mathrm{mEq} / \mathrm{L})$ in conjunction with multiple other factors included in the model.

This study is limited by its observational design, and hence can only provide aggregated measurements and associations. Moreover, patient symptoms were not collected. This limits comparisons with other studies that correlate outcomes with symptomatic IH rather than simply measured decreases in SBP. The associations between $\mathrm{IH}$ and mortality and hospitalization were limited by the relatively short follow-up time and limited number of deaths and hospitalizations. Additionally, limiting the subset analysis of mortality and hospitalization to patients with more than 20 recorded treatments may introduce bias because patients had to survive a minimum of 20 treatments, and therefore may have comprised a group of healthier patients. Lastly, the associations between IH and mortality and hospitalization may represent markers of patients' underlying disease state rather than IH per se as an independent causative factor. ${ }^{5}$ However, this limitation may be mitigated by previous reports linking IH to myocardial stunning; which suggests a potential causative role for IH in ongoing patient morbidity. ${ }^{9}$

\section{CONCLUSION}

$\mathrm{IH}$ is common and highly variable by patient and facility. The risk of IH was associated with demographic factors, presence of diabetes, longer dialysis vintage, higher BMI and UFV, failure to achieve prescribed target post-HD weight, a lower pre-HD SBP, and higher dialysate temperature. IH risk was independently associated with specific dialysis facilities, suggesting an effect of practice patterns. IH frequency was also associated with mortality and hospitalization. Critical evaluation of facility practice patterns and potential modifiable risk factors coupled with routine standardized reporting of IH may reduce the frequency of $\mathrm{IH}$ and decrease patient mortality, hospitalizations, and cost of care.

\section{ACKNOWLEDGMENTS}

The authors wish to acknowledge the contributions of Terri Neal, Gloria Saunders Bassett, Han Cho, and Dan Riso, whose efforts made the direct data capture possible and the efforts and support of the nurses, staff, and physicians at the RRI facilities. Portions of these data were presented in abstract form at the 2011 American Society of Nephrology Annual Meeting and at the 2013 Annual Dialysis Conference.

\section{SUPPORT AND FINANCIAL DISCLOSURE DECLARATION}

Institutional support: research support for this study was provided by Fresenius Medical Care North America. Jeffrey J. Sands, MD MMM, Len Usvyat, Paul Zabetakis, MD, Franklin W. Maddux, MD, and Jose A. Diaz-Buxo, MD are employed by the Fresenius Medical Care North America; Terry Sullivan is employed by the Renal Research Institute New York; and Peter Kotanko, MD is employed by the Renal Research Institute New York and holds stock in the Fresenius Medical Care. Jonathan H. Segal, MD has no disclosure.

Manuscript received October 2013; revised December 2013.

\section{REFERENCES}

1 Sherman R. Intradialytic hypotension: An overview of recent, unresolved and overlooked issues. Semin Dial. 2002; 15:141-143.

2 Davenport A, Cox C, Thuraisingham R. Blood pressure control and symptomatic intradialytic hypotension in diabetic haemodialysis patients: A cross-sectional survey. Nephron Clin Pract. 2008; 109:c65-c71.

3 Davenport A, Cox C, Thuraisingham R. Achieving blood pressure targets during dialysis improves control but increases intradialytic hypotension. Kidney Int. 2008; 73:759-764. 
4 Palmer BF, Henrich WL. Recent advances in the prevention and management of intradialytic hypotension. J Am Soc Nephrol. 2008; 19:8-11.

5 Tislér A, Akócsi K, Borbás B, et al. The effect of frequent or occasional dialysis-associated hypotension on survival of patients on maintenance haemodialysis. Nephrol Dial Transplant. 2003; 18:2601-2605.

6 Shoji T, Tsubakihara Y, Fujii M, Imai E. Hemodialysisassociated hypotension as an independent risk factor for two-year mortality in hemodialysis patients. Kidney Int. 2004; 66:1212-1220.

7 Henderson LW. Symptomatic intradialytic hypotension and mortality: An opinionated review. Semin Dial. 2012; 25:320-325.

8 Chang TI, Paik J, Greene T, et al. Intradialytic hypotension and vascular access thrombosis. J Am Soc Nephrol. 2011; 22:1526-1533.

9 McIntyre CW. Haemodialysis-induced myocardial stunning in chronic kidney disease-A new aspect of cardiovascular disease. Blood Purif. 2010; 29:105-110.

10 Dinesh K, Kunaparaju S, Cape K, Flythe JE, Feldman HI, Brunelli SM. A model of systolic blood pressure during the course of dialysis and clinical factors associated with various blood pressure behaviors. Am J Kidney Dis. 2012; 59:409-418.

11 Flyth JE, Kimmel SE, Brunelli SM. Rapid fluid removal during dialysis is associated with cardiovascular morbidity and mortality. Kidney Int. 2011; 79:250-257.

12 Lai CT, Wu CJ, Chen HH, et al. Absolute interdialytic weight gain is more important than percent weight gain for intradialytic hypotension in heavy patients. Nephrology (Carlton). 2012; 17:230-236.

13 Kaufman AM, Morris AT, Lavarias VA, et al. Effects of controlled blood cooling on hemodynamic stability and urea kinetics during high-efficiency hemodialysis. J Am Soc Nephrol. 1998; 9:877-883.

14 Chesterton LJ, Selby NM, Burton JO, McIntyre CW. Cool dialysate reduces asymptomatic intradialytic hypotension and increases baroreflex variability. Hemodial Int. 2009; 13:189-196.

15 Murashima M, Kumar D, Doyle AM, Glickman JD. Comparison of intradialytic blood pressure variability between conventional thrice-weekly hemodialysis and short daily hemodialysis. Hemodial Int. 2010; 14:270277.

16 Locatelli F, Altieri P, Andrulli S, et al. Hemofiltration and hemodiafiltration reduce intradialytic hypotension in ESRD. J Am Soc Nephrol. 2010; 21:1798-1807.

17 Prakash S, Garg AX, Heidenheim AP, House AA. Midodrine appears to be safe and effective for dialysis-induced hypotension: A systematic review. Nephrol Dial Transplant. 2004; 19:2553-2558.

18 Imai E, Fujii M, Kohno Y, et al. Adenosine Al receptor antagonist improves intradialytic hypotension. Kidney Int. 2006; 69:877-883.

19 Alappan R, Cruz D, Abu-Alfa AK, Mahnensmith R, Perazella MA. Treatment of severe intradialytic hypotension with the addition of high dialysate calcium concentration to midodrine and/or cool dialysate. Am J Kidney Dis. 2001; 37:294-299.

20 Schmidt R, Roeher O, Hickstein H, Korth S. Prevention of haemodialysis-induced hypotension by biofeedback control of ultrafiltration and infusion. Nephrol Dial Transplant. 2001; 16:595-603.

21 van der Sande FM, Kooman JP, Leunissen KM. Intradialytic hypotension-new concepts on an old problem. Nephrol Dial Transplant. 2000; 15:1746-1748.

22 Maduell F, Moreso F, Pons M, et al. High-efficiency postdilution online hemodiafiltration reduces all-cause mortality in hemodialysis patients. J Am Soc Nephrol. 2013; 24:487-497.

23 Robinson BM, Bieber B, Pisoni RL, Port FK. Public Policy Series: Dialysis Outcomes and Practice Patterns Study (DOPPS): Its strengths, limitations, and role in informing practices and policies. Clin J Am Soc Nephrol. 2012; 7:1897-1905. 